\title{
The prevalence of headache disorders in children and adolescents in Lithuania: a schools-based study
}

Diana Genc ${ }^{1}$, Nerija Vaičienè-Magistris ${ }^{1}$, Apolinaras Zaborskis² ${ }^{2}$ Tayyar Şaşmaz ${ }^{3}$, Aylin Yeniocak Tunç3 Derya Uluduz ${ }^{4}$ and Timothy J. Steiner ${ }^{5,6^{*}}$

\begin{abstract}
Background: While the Global Burden of Disease (GBD) study reports headache disorders as the second-highest cause of disability worldwide, the headache data in GBD come very largely from adults. This national study in Lithuania was part of a global schools-based programme within the Global Campaign against Headache contributing data from children (7-11 years) and adolescents (12-17 years).
\end{abstract}

Methods: The methods followed the generic protocol for the global study. The basic study design was a crosssectional survey. Self-completed structured questionnaires were administered, within classes, in 24 schools selected from seven regions of Lithuania to be nationally representative. Headache diagnostic questions were based on ICHD-3 beta criteria but for the inclusion of undifferentiated headache $(\mathrm{UdH})$.

Results: Of 3714 potential participants, 2505 (children 1382 [55.2\%], adolescents 1123 [44.8\%]; males 1169 [46.7\%], females 1336 [53.3\%]) completed the questionnaire. Adolescents and males were therefore relatively under-represented, with non-participation (32.6\%) due in most cases to lack of parental consent. Observed lifetime prevalence of headache was 92.2\%. Gender- and age-adjusted 1-year prevalence was 76.6\% (migraine: 21.4\%; tension-type headache [TH]: 25.6\%; $\mathrm{UdH}: 24.0 \%$; all headache on $\geq 15$ days/month: 3.9\%; probable medication-overuse headache: $0.8 \%$ ). All headache types except $\mathrm{UdH}$ were more prevalent among females than males, and among adolescents than children. UdH showed a complex relationship with age, but represented $38.0 \%$ of all reported headache in children, $27.4 \%$ in adolescents. Headache yesterday $(\mathrm{HY})$ was reported by $17.5 \%$, almost double the $9.8 \%$ predicted from prevalence and headache frequency to have headache on any day. The reason was unclear.

Conclusions: Findings were not very different from those reported in Turkey and Austria, but with more TTH. Headache has, therefore, again been shown to be common in children and adolescents, and UdH confirmed as a headache type that must be recognised and included in accounts of headache in these age groups.

Keywords: Child and adolescent headache, Migraine, Tension-type headache, Medication-overuse headache, Undifferentiated headache, Epidemiology, Prevalence, Schools-based study, Lithuania, Global campaign against headache

\footnotetext{
* Correspondence: t.steiner@imperial.ac.uk

${ }^{5}$ Department of Neuromedicine and Movement Science, Norwegian University of Science and Technology, Edvard Griegs gate, Trondheim, Norway

${ }^{6}$ Division of Brain Sciences, Imperial College London, London, UK

Full list of author information is available at the end of the article
}

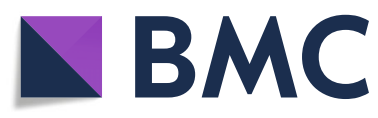

(- The Author(s). 2020 Open Access This article is licensed under a Creative Commons Attribution 4.0 International License, which permits use, sharing, adaptation, distribution and reproduction in any medium or format, as long as you give appropriate credit to the original author(s) and the source, provide a link to the Creative Commons licence, and indicate if changes were made. The images or other third party material in this article are included in the article's Creative Commons licence, unless indicated otherwise in a credit line to the material. If material is not included in the article's Creative Commons licence and your intended use is not permitted by statutory regulation or exceeds the permitted use, you will need to obtain permission directly from the copyright holder. To view a copy of this licence, visit http://creativecommons.org/licenses/by/4.0/ The Creative Commons Public Domain Dedication waiver (http://creativecommons.org/publicdomain/zero/1.0/) applies to the data made available in this article, unless otherwise stated in a credit line to the data. 


\section{Introduction}

While multiple iterations of the Global Burden of Disease (GBD) study have shown headache disorders to be a major cause of public ill health worldwide [1-6], the data for headache in GBD have, so far, come very largely from adults. The prevalence and burden of headache disorders in children and adolescents are not well characterised and in many parts of the world are unmeasured.

A global study of child and adolescent headache is consequently underway: it is an essential part of the endeavour by the Global Campaign against Headache, under the direction of Lifting The Burden (LTB) [7-10], to measure the scale and scope of headache-attributed burden worldwide [7-9]. The intention, in this schoolsbased programme, is to cluster-sample the world, gathering data according to a standardised protocol [11] from at least 20 countries spread through the world's six major regions. The protocol was piloted in Turkey and Austria [11-13].

The programme focuses on the headache disorders with public-health importance not only in children and adolescents but also in adults: migraine, tension-type headache $(\mathrm{TTH})$ and the group of headache disorders characterised by headache occurring on $\geq 15$ days per month, including medication-overuse headache (MOH). These disorders in adults have very commonly had their onset in pre-adult years. However, the studies from Turkey and Austria showed a high prevalence of undifferentiated headache (UdH), not diagnosable as migraine or TTH $[12,13]$, which is therefore included in studies within this programme. By definition, this type of headache is mild and of short duration $(<1 \mathrm{~h})$ [12].

This national study in Lithuania, of children aged 7-11 years and adolescents aged $12-17$ years, was a part of the global schools-based programme. Because institutional schooling is mandatory for 10 years in Lithuania, from ages 6.5 or 7.5 years depending on month of birth, and about $90 \%$ of pupils continue for another 2 years, schools-based sampling was methodologically valid for these age groups [14]. The aims of the study were to estimate the prevalences of these headache disorders in these age groups, reported here, and their attributed burden, to be reported later. The purposes were to inform not only GBD but also local health policy.

\section{Methods}

The basic study design was a cross-sectional survey conducted by self-completed structured questionnaire administered in schools selected to be nationally representative. The methods have been published earlier [15], as has the generic protocol [11].

\section{Ethics and approvals}

The study was approved by Kaunas Regional Committee of Bioethics (BE-2-7, 26-01-2016), and authorised, as required, by Regional Education Authorities.

School managers and teachers at the selected schools agreed to participation. Consent of each participating child or adolescent was obtained prior to recruitment, along with written parental consent. For these purposes, information sheets were prepared for potential participants and their parents, describing the nature and purposes of the survey. These were distributed to pupils in the participating schools 1 week before the study start. On the day of the study, pupils who were willing, and possessed a consent form signed by a parent, were invited to complete the questionnaire.

Data were collected anonymously. Data protection legislation was complied with.

\section{Sampling and recruitment}

The survey was conducted in Spring, 2016.

We randomly selected 24 schools located in seven regions of Lithuania (Fig. 1), the latter purposively chosen to represent the country's limited geographical and socioeconomic diversities. All classes in each school across the age ranges 7-11 years and/or 12-17 years, and all pupils in each such class, except those for whom parental consent had not been given, were invited to participate. Pupils who refused on their own account to take part for any reason were excluded, along with those absent from school on the day. All but the last group were counted as non-participants.

\section{Numbers}

Published recommendations on sample size calculation for headache prevalence [14] suggest limited gain from samples greater than $N=2000$. For burden, larger numbers may be more informative, but there is no good basis for power calculation, given the multiple components of burden [14]. Our aim here was for 200 evaluable participants of each age 7-17 years, drawn approximately equally from the participating schools (expected totals of 1000 children and 1200 adolescents).

\section{Survey instrument}

We employed the child and adolescent versions of LTB's Headache-Attributed Restriction, Disability, Social Handicap and Impaired Participation (HARDSHIP) structured questionnaire [11], translated into Lithuanian language according to LTB's translation protocol for hybrid documents [16]. These modular instruments, designed for application by lay interviewers, incorporated demographic enquiry, headache screening and diagnostic questions based on ICHD-3 beta criteria [17] and enquiries into components of headache-attributed burden. The timeframe of enquiry 


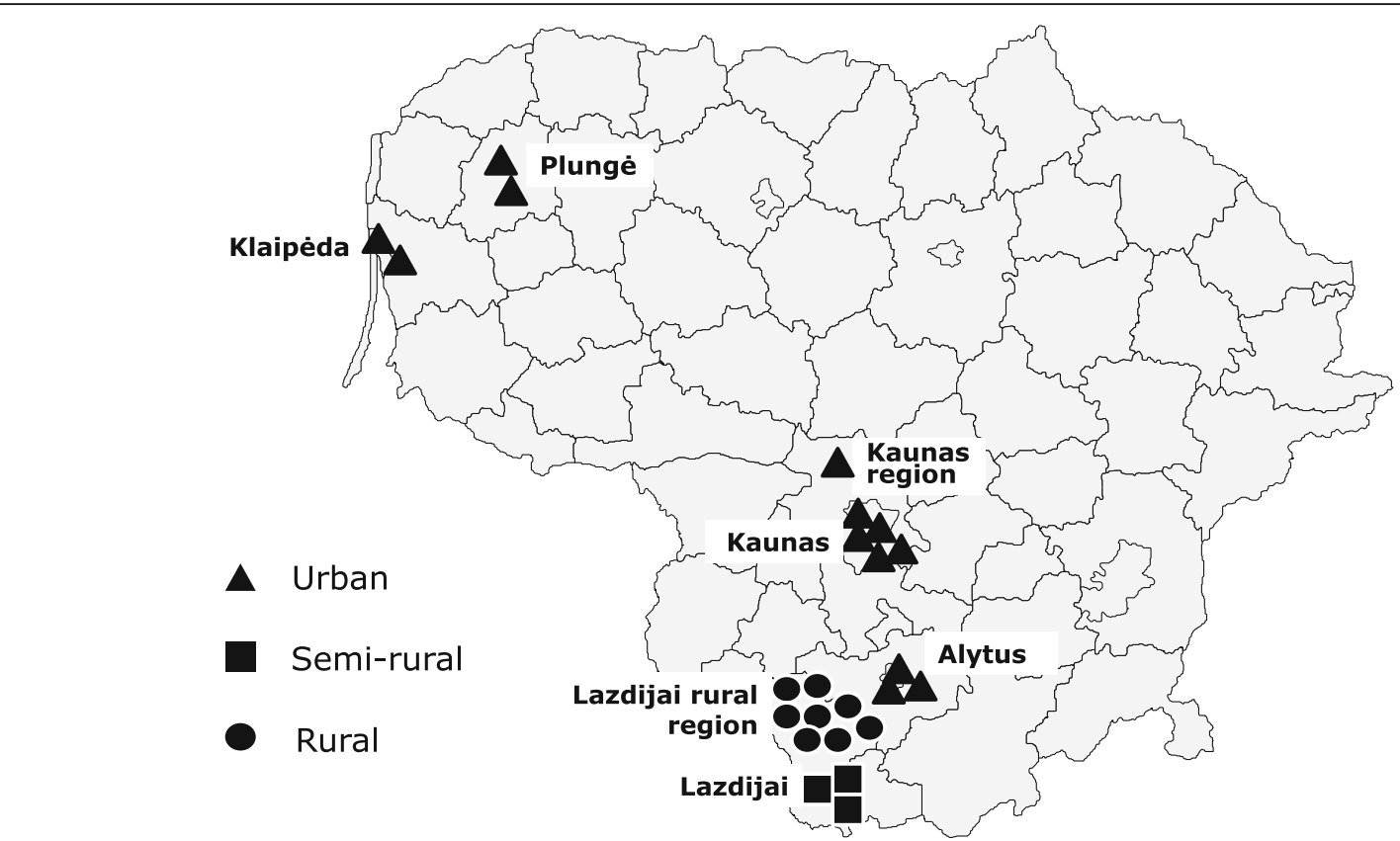

Fig. 1 Location of 24 selected schools within seven regions of Lithuania

was the preceding 4 weeks ( 28 days), except for the module asking specifically about headache yesterday (HY).

These questionnaires were administered to the pupils in class, who completed them anonymously under the supervision of an investigator, a previously instructed school public-health specialist and/or a teacher. After an initial introduction, adolescents, and children competent in reading, completed their questionnaires independently, without further assistance. Children aged 7 or 8 years, and a few older children with learning difficulties, were assisted as necessary.

Additional questionnaires addressed to teachers enquired into relevant school variables.

\section{Diagnoses}

Diagnoses were made algorithmically according to HARDSHIP methodology [11, 18]. Headache on $\geq 15$ days/month (ie, reported on $\geq 14$ days in the preceding 4 weeks) was first identified, and categorised according to reported medication use into probable $\mathrm{MOH}$ (pMOH: use on $\geq 14$ days/4 weeks) or "other headache on $\geq 15$ days/month" (use on $0-13$ days/4 weeks). To all other reported headaches, the algorithm first applied criteria for UdH (mild intensity and usual duration $<1 \mathrm{~h}$ [12]) and then the ICHD-3 beta criteria [17], with one important modification, for definite migraine, definite TTH, probable migraine and probable TTH in this strict order [18]. The modification, to accommodate the definition of $\mathrm{UdH}$, was to raise the lower duration limit of TTH from $30 \mathrm{~min}$ to $1 \mathrm{~h}$ [12]. Remaining cases, if any, were unclassified.

\section{Data management and entry}

Completed questionnaires were removed to the Department of Preventive Medicine and Health Research Institute at Lithuanian University of Health Sciences in Kaunas, and held securely during data entry into an electronic database. As a quality-control measure, we performed independent double data-entry with reconciliation of discrepancies by comparison with source data.

\section{Analysis}

Analyses were performed at University of Mersin.

We categorised schools by locality (urban, semi-rural, rural) and by estimated proportions of pupils coming from low-income homes $(<0.25,0.25-0.5,0.5-0.75$ [categories referred to for simplicity as "high-income", "middle-income" and "low-income"]). We used descriptive statistics to present means and standard deviations (SDs) of continuous variables and proportions (\%) with 95\% confidence intervals (CIs) of categorical data. We used chi-squared or one-sample proportion tests to evaluate differences between groups. We estimated prevalences of each headache type as proportions (\%) with 95\% CIs, and adjusted the observed values for gender and age using official population statistics for Lithuania [19]. In these analyses, definite and probable migraine were combined, as were definite and probable TTH $[14,18]$. To show associations with demographic variables, we first used bivariate analysis with odds ratios (ORs), then multivariate analysis with adjusted ORs (AORs), entering gender, age group, school locality and income category into the multivariate model. Mean headache frequencies 
(days/month) were calculated to support estimates of predicted headache yesterday.

We considered $p<0.05$ to be significant.

\section{Results}

According to class lists, the sampled population consisted of 4019 children and adolescents (male 2016 [50.2\%], female 2003 [49.8\%]), but 305 (7.6\%) were absent on the day. Of the 3714 potential participants, 897 (24.2\%) did not or could not provide parental consent and another $312(8.4 \%)$ did not themselves consent, with more males $(55.9 \%)$ than females $(44.1 \%)$ among these. The non-participation proportion was $32.6 \%$. Among actual participants $(N=2505$; male 1169 [46.7\%], female 1336 [53.3\%]), males were under-represented (46.7\% against $50.2 \%$ expected; females $53.3 \%$ against $49.8 \%$ expected; one sample proportion test: $p<0.001$ [2-tailed]).

There were 1382 children (55.2\%) and 1123 adolescents (44.8\%), with overall mean age of $11.5 \pm 3.2$ years (median 11). Since we intended to have similar numbers of each age group, children were relatively over-sampled. School variables are shown in Table 1. Most participants (66.3\%) attended urban schools. A substantial minority (20.3\%) attended schools where $>50 \%$ of pupils were from low-income homes, these also being the rural schools (Table 1).

\section{Headache}

Headache ever was reported by 2309 participants (observed lifetime prevalence $=92.2 \%$ ). Headache in the preceding year was reported by 1858 (observed 1-year prevalence $=74.2 \%$; gender - and age-adjusted: $76.6 \%$ ) . Observed and adjusted prevalences of each headache type are shown in Table 2.

TTH (25.6)\% and UdH (24.0\%) were the most common headache types after adjustment, with migraine not very far behind (21.4\%) (Table 2). Headache on $\geq 15$ days/month affected almost one participant in 25 (3.9\%),

Table 1 School variables (from teachers' questionnaires), and numbers of participant pupils affected $(N=2505)$

\begin{tabular}{|c|c|c|c|}
\hline \multirow[t]{2}{*}{ Variable } & \multirow{2}{*}{$\begin{array}{l}\text { Schools } \\
\text { n }\end{array}$} & \multicolumn{2}{|l|}{ Pupils } \\
\hline & & $\mathrm{n}$ & $\%$ \\
\hline \multicolumn{4}{|l|}{ School locality } \\
\hline urban & 13 & 1660 & 66.3 \\
\hline semi-rural & 3 & 336 & 13.4 \\
\hline rural & 8 & 509 & 20.3 \\
\hline \multicolumn{4}{|c|}{$\begin{array}{l}\text { Income category according to estimated proportion of pupils from low } \\
\text { income homes }\end{array}$} \\
\hline < 0.25 ("high-income" school) & 13 & 1828 & 73.0 \\
\hline 0.25-0.5 ("middle-income" school) & 3 & 168 & 6.7 \\
\hline 0.5-0.75 ("low-income" school) & 8 & 509 & 20.3 \\
\hline
\end{tabular}

who reported headache on a mean of 18.7 days/4 weeks. These included $0.8 \%$ with $\mathrm{pMOH}$, who reported headache and medication use on 19.7 and 18.2 days/4 weeks respectively. There were 42 headaches cases (1.7\%) remaining unclassified.

\section{Demographic associations}

These are illustrated in Tables 2, 3, 4. All headache types except $\mathrm{UdH}$ were more prevalent among females than males, and among adolescents than children. $\mathrm{UdH}$ showed a complex relationship with age. In absolute terms, its prevalence increased from $19.3 \%$ at ages $7-8$ years to a maximum of $30.7 \%$ at ages $11-12$, then declined to a minimum of $18.1 \%$ at 17 years. This was against a background of increasing prevalence of all other headache types, so that $\mathrm{UdH}$ represented $38.0 \%$ of all reported headache in children, but only $27.4 \%$ in adolescents. Headache on $\geq 15$ days/month ( $\mathrm{pMOH}$ : OR $=$ 5.0; other: $\mathrm{OR}=3.5$ [Table 3]) was much more common among adolescents.

Associations with income category apparent on bivariate analysis (Table 3) lost significance in multivariate analysis, with location factored in (Table 4). Migraine was less prevalent, and UdH more prevalent, in rural schools than others (Tables 2, 3, 4).

\section{Headache yesterday (HY)}

HY was reported by 438 participants $(17.5 \%$ of the total sample; $23.6 \%$ of those with any headache) (Table 5).

Mean headache frequency in the 1858 reporting any headache was $3.7 \pm 4.5$ days $/ 4$ weeks. Probability of HY among these, calculated as proportion of days affected, was $13.2 \%(3.7 / 28)$. Since observed prevalence of all headache $=74.2 \%$ (Table 2), $9.8 \%$ of all participants $(74.2 * 13.2 \%)$ would be expected to have headache on any day (predicted HY). In fact, participants with all episodic headache types reported substantially more HY than predicted, notably those with migraine (by a factor of 2.2) (Table 5). Headache on $\geq 15$ days/month, particularly $\mathrm{pMOH}$, was reported yesterday only slightly more than predicted. These disorders were, of course, the greatest contributors proportionately to HY (by definition, $>50 \%$ would be expected), but their low prevalence limited their overall impact. Females reported HY more than males (OR: 2.0 [1.6-2.5]; $p<0.001$ ), but adolescents no more than children (OR; $1.1[0.9-1.3] ; p=$ 0.5727).

\section{Discussion}

This was the second national study of child and adolescent headache to be completed within the Global Campaign programme of such studies. In summary, it found headache to be very common in these age groups in Lithuania, with over three quarters (76.6\%) affected. 
Table 2 Crude (observed) prevalences of all headache and each headache type, overall and according to demographic variables, and gender- and age-adjusted prevalences $(N=2505)$

\begin{tabular}{|c|c|c|c|c|c|c|}
\hline & All headache $(n=1858)$ & Migraine $(n=519)$ & $\mathrm{TTH}(n=605)$ & $\mathrm{pMOH}(n=18)$ & $\begin{array}{l}\text { Other headache on } \\
\geq 15 \mathrm{~d} / \mathrm{m}(n=73)\end{array}$ & $\mathrm{UdH}(n=601)$ \\
\hline \multicolumn{7}{|c|}{ Observed prevalences (\% $[95 \% \mathrm{CI}]$ ) } \\
\hline Overall & $74.2[72.5-75.9]$ & $20.7[19.1-22.3]$ & $24.2[22.5-25.9]$ & $0.7[0.4-1.0]$ & $2.9[2.2-3.6]$ & $24.0[22.3-25.7]$ \\
\hline \multicolumn{7}{|l|}{ Gender } \\
\hline male $(n=1169)$ & $67.8[65.1-70.5]$ & $18.6[16.4-20.8]$ & $22.3[19.9-24.7]$ & $0.2[0.0-0.5]$ & $1.5[0.8-2.2]$ & $24.0[21.7-26.3]$ \\
\hline female $(n=1336)$ & $79.7[77.5-81.9]$ & $22.5[20.3-24.7]$ & $25.8[23.5-28.1]$ & $1.2[0.6-1.8]$ & $4.2[3.1-5.3]$ & $24.0[21.6-26.5]$ \\
\hline \multicolumn{7}{|l|}{ Age group (years) } \\
\hline $7-11(n=1382)$ & $62.7[60.2-65.2]$ & 17.9 [15.9-19.9] & $17.5[15.5-19.5]$ & $0.3[0.0-0.6]$ & $1.3[0.7-1.9]$ & $23.8[21.6-26.1]$ \\
\hline $12-17(n=1123)$ & $88.3[86.4-90.2]$ & $24.2[21.7-26.7]$ & $32.3[29.6-35.0]$ & $1.3[0.6-2.0]$ & $4.9[3.6-6.2]$ & $24.2[21.7-26.7]$ \\
\hline \multicolumn{7}{|c|}{ School income category* } \\
\hline high $(n=1828)$ & $75.6[73.6-77.6]$ & $21.8[19.9-23.7]$ & $25.7[23.7-27.7]$ & $0.7[0.3-1.1]$ & $3.1[2.3-3.9]$ & $22.5[20.6-24.4]$ \\
\hline middle $(n=168)$ & $61.9[54.6-69.2]$ & 20.8 [14.7-26.9] & $16.1[10.5-21.7]$ & $0.6[0.0-1.8]$ & $1.2[0.0-2.8]$ & $22.0[15.7-28.3]$ \\
\hline low $(n=509)$ & $73.1[69.2-77.0]$ & 16.9 [13.6-20.2] & $21.4[17.8-25.0]$ & $0.8[0.0-1.6]$ & $2.9[1.4-4.4]$ & $29.9[25.9-33.9]$ \\
\hline \multicolumn{7}{|l|}{ School locality } \\
\hline urban $(n=1660)$ & $73.3[71.2-75.4]$ & $21.6[19.6-23.6]$ & $24.8[22.7-26.9]$ & $0.7[0.3-1.1]$ & $2.5[1.7-3.3]$ & $22.0[20.0-24.0]$ \\
\hline semi-rural $(n=336)$ & $79.5[75.2-83.8]$ & $22.3[17.8-26.8]$ & $25.3[20.7-29.9]$ & $0.9[0.0-1.9]$ & $4.8[2.5-7.1]$ & $24.7[20.1-29.3]$ \\
\hline rural $(n=509)$ & $73.1[69.2-77.0]$ & $16.9[13.6-20.2]$ & $21.4[17.8-25.0]$ & $0.8[0.0-1.6]$ & $2.9[1.4-4.4]$ & $29.9[25.9-33.9]$ \\
\hline \multicolumn{7}{|c|}{ Gender and age-adjusted prevalences $(\%[95 \% \mathrm{Cl}])$} \\
\hline Overall & $76.6[74.9-78.3]$ & $21.4[19.8-23.0]$ & $25.6[23.9-27.3]$ & $0.8[0.5-1.2]$ & $3.1[2.4-3.8]$ & $24.0[22.3-25.7]$ \\
\hline
\end{tabular}

$\pi \mathrm{H}$ tension-type headache, $\mathrm{pMOH}$ probable medication-overuse headache, $d / m$ days/month, $U d \mathrm{H}$ undifferentiated headache, $\mathrm{Cl}$ confidence interval; * see text or Table 1 for explanation. Tables 3 and 4 provide odds ratios and adjusted odds ratios for these comparisons

TTH (25.6\%) and UdH (24.0\%) accounted for most, but migraine was also prevalent (21.4\%). Headache on $\geq 15$ days/month was far from rare (3.9\%), although pMOH was found in only $0.8 \%$. HY was reported by more than one in six participants (17.5\%). Associations with age and gender were much as expected, although we say more below about the relationship between $\mathrm{UdH}$ and age. Migraine was less prevalent, and UdH more prevalent, suggesting a lower rate of headache differentiation, in rural schools than others. We attach no importance to this. There were no clear associations with income category.

Lithuania and Turkey (venue for the first study) are both in the European Region, but not close geographically, ethnically or culturally. Comparisons between these are of particular interest because the studies in each used the same methodology and questionnaires. The Turkish study $(N=7088)$ has not yet been fully reported, but published analysis so far has shown a prevalence of $\mathrm{UdH}$ of $29.2 \%$, of migraine $26.7 \%$ and of TTH $12.9 \%$ [12]. UdH and migraine were therefore slightly more common in Turkey, but of similar proportions in relation to each other, while TTH in Turkey had only half the prevalence of TTH in Lithuania.

The study in Austria had different sampling methodology and included ages 10-18 years only, but used the same questionnaire [13]. This found a prevalence of $\mathrm{UdH}$ of $26.1 \%$, of migraine $24.2 \%$, of TTH $21.6 \%$ and of headache on $\geq 15$ days/month of $3.0 \%$ - all similar to our findings in adolescents in Lithuania, except again, perhaps, for TTH. Speculation on the reason for the differences in TTH would probably be idle until more studies have been completed and ranges established in these age groups for the prevalence of each headache type.

The crucial finding here is that this study in Lithuania confirms the importance - postulated in the earlier studies $[12,13]$ - of including $\mathrm{UdH}$ in prevalence (and burden) estimates in these age groups. In our study it accounted for one third of all reported headache, as it did in Austria [13] (in Turkey the proportion was about $40 \%$ [12]). UdH is believed to represent immature forms of migraine and TTH [12], or, more correctly perhaps, migraine or $\mathrm{TTH}$ expressed by an immature brain, so that the characteristic features of these headaches have yet to develop. Short duration $(<1 \mathrm{~h})$ is one manifestation of this. According to this belief, UdH should become less common with aging from childhood into adolescence, while migraine and TTH increase in prevalence as UdH evolves into one or the other. UdH did, indeed, reduce in this study from $38.0 \%$ of all reported headache in children to $27.4 \%$ in adolescents. The complex relationship seen between $\mathrm{UdH}$ and age can be 
Table 3 Bivariate logistic regression analyses of headache type versus demographic variables $(N=2505)$

\begin{tabular}{|c|c|c|c|c|c|}
\hline \multirow[t]{2}{*}{ Variable } & Migraine & $\mathrm{TTH}$ & $\mathrm{pMOH}$ & Other headache on $\geq 15 \mathrm{~d} / \mathrm{m}$ & $\mathrm{UdH}$ \\
\hline & \multicolumn{5}{|c|}{ Odds ratio $[95 \% \mathrm{Cl}]$} \\
\hline \multicolumn{6}{|l|}{ Gender } \\
\hline male $(n=1169)$ & reference & reference & reference & reference & reference \\
\hline female $(n=1336)$ & $1.2[1.0-1.5]$ & $1.2[1.01-1.5]^{1}$ & $7.1[1.6-30.8]^{2}$ & $3.0[1.7-5.1]^{4}$ & $1.0[0.8-1.2]$ \\
\hline \multicolumn{6}{|l|}{ Age group (years) } \\
\hline $7-11(n=1382)$ & reference & reference & reference & reference & reference \\
\hline $12-17(n=1123)$ & $1.5[1.2-1.8]^{4}$ & $2.2[1.9-2.7]^{4}$ & $4.3[1.4-13.2]^{2}$ & $3.9[2.3-6.7]^{4}$ & $1.0[0.85-1.2]$ \\
\hline \multicolumn{6}{|l|}{ School income category* } \\
\hline high $(n=1828)$ & reference & reference & reference & reference & reference \\
\hline middle or low $(n=677)$ & $0.8[0.6-0.98]^{1}$ & $\mathbf{0 . 7}[0.6-0.9]^{2}$ & $1.0[0.4-2.9]$ & $0.8[0.5-1.4]$ & $1.3[1.1-1.6]^{2}$ \\
\hline \multicolumn{6}{|l|}{ School locality } \\
\hline urban $(n=1660)$ & reference & reference & reference & reference & reference \\
\hline semi-rural $(n=336)$ & $1.0[0.8-1.4]$ & $1.0[0.8-1.3]$ & $1.4[0.4-4.9]$ & $1.9[1.1-3.5]^{1}$ & $1.2[0.9-1.5]$ \\
\hline rural $(n=509)$ & $0.7[0.6-0.96]^{1}$ & $0.8[0.7-1.05]$ & $1.2[0.4-3.7]$ & $1.2[0.6-2.1]$ & $\mathbf{1 . 5}[1.2-1.9]^{3}$ \\
\hline
\end{tabular}

$\pi \mathrm{H}$ tension-type headache, $\mathrm{pMOH}$ probable medication-overuse headache, $d / \mathrm{m}$ days/month, $\mathrm{UdH}$ undifferentiated headache, $\mathrm{Cl}$ confidence interval; ${ }^{*}$ see text or Table 1 for explanation; significant values are emboldened: ${ }^{1} p<0.05 ;{ }^{2} p<0.01 ;^{3} p<0.001 ;{ }^{4} p \leq 0.0001$

explained by the interaction of these two factors: on the one hand, an overall increase in headache prevalence with increasing age; on the other, increasing headache differentiation, so that UdH declined with age as a proportion of all headache.

We have data available on adult headache in Lithuania, obtained through the Eurolight study [20], also a Global Campaign project [21]. It was conducted by visiting homes, and was smaller $(N=573)$, but used very similar diagnostic questions from the adult version of HARDSHIP $[18,21]$. Gender-adjusted 1-year prevalence of migraine was $18.8 \%$ [15.9-22.3\%] and of TTH $42.2 \%$ [38.3-46.3\%], the former being lower and the latter higher than we saw in children and adolescents. Comparisons should be circumspect, because the adult study was limited in geographical scope (to Kaunas city and surrounding Kaunas region [21]). However, Lithuania is a small and rather homogeneous country. The bigger problem with the adult study was a non-participation proportion of $49.6 \%$ [21], very likely to introduce bias. Our interest is raised, nonetheless, by the prevalences in the adult study of pMOH $(3.2 \%$ [2.0-4.9\%]) and other

Table 4 Multivariate logistic regression analyses of headache type versus demographic variables $(N=2505)$

\begin{tabular}{|c|c|c|c|c|c|}
\hline \multirow[t]{2}{*}{ Variable } & Migraine & $\mathrm{TTH}$ & $\mathrm{pMOH}$ & Other headache on $\geq 15 \mathrm{~d} / \mathrm{m}$ & $\mathrm{UdH}$ \\
\hline & \multicolumn{5}{|c|}{ Adjusted odds ratio $[95 \% \mathrm{Cl}]^{*}$} \\
\hline \multicolumn{6}{|l|}{ Gender } \\
\hline male $(n=1169)$ & reference & reference & reference & reference & reference \\
\hline female $(n=1336)$ & $1.25[1.03-1.5]^{1}$ & $1.2[0.97-1.4]$ & $6.8[1.6-28.9]^{1}$ & $2.8[1.6-4.9]^{1}$ & $0.99[0.8-1.2]$ \\
\hline \multicolumn{6}{|l|}{ Age group (years) } \\
\hline $7-11(n=1382)$ & reference & reference & reference & reference & reference \\
\hline $12-17(n=1123)$ & $\mathbf{1 . 5}[1.2-1.9]^{2}$ & $2.25[1.85-2.75]^{2}$ & $5.0[1.4-17.7]^{1}$ & $3.5[2.0-6.2]^{2}$ & $0.99[0.8-1.2]$ \\
\hline \multicolumn{6}{|l|}{ School income category* } \\
\hline high $(n=1828)$ & $0.8[0.5-1.2]$ & $1.1[0.7-1.75]$ & $0.3[0.03-3.6]$ & $1.3[0.3-6.1]$ & $1.1[0.7-1.7]$ \\
\hline middle or low $(n=677)$ & reference & reference & reference & reference & reference \\
\hline \multicolumn{6}{|l|}{ School locality } \\
\hline urban $(n=1660)$ & reference & reference & reference & reference & reference \\
\hline semi-rural $(n=336)$ & $0.9[0.7-1.2]$ & $0.9[0.65-1.2]$ & $0.9[0.2-3.3]$ & $1.5[0.8-2.8]$ & $1.2[0.9-1.6]$ \\
\hline rural $(n=509)$ & $0.6[0.36-0.96]^{1}$ & $0.9[0.5-1.4]$ & $0.4[0.03-5.0]$ & $1.4[0.3-7.3]$ & $1.7[1.06-2.7]^{1}$ \\
\hline
\end{tabular}

$\pi \mathrm{H}$ tension-type headache, $\mathrm{pMOH}$ probable medication-overuse headache, $d / m$ days/month, $U d \mathrm{H}$ undifferentiated headache, $\mathrm{Cl}$ confidence interval; ${ }^{*}$ see text or Table 1 for explanation; significant values are emboldened: ${ }^{1} p<0.05 ;^{2} p<0.001$ 
Table 5 Proportions reporting headache yesterday, and predicted proportions ${ }^{a}$, overall and by headache type $(N=2505)$

\begin{tabular}{|c|c|c|c|}
\hline \multirow[t]{3}{*}{ Headache type } & \multicolumn{3}{|c|}{ Headache yesterday } \\
\hline & \multirow{2}{*}{$\begin{array}{l}\text { Reported } \\
\text { proportion } \\
\mathrm{n}(\%)\end{array}$} & \multicolumn{2}{|l|}{ Predicted proportion } \\
\hline & & Mean reported headache frequency (F) (days/4 weeks) & Predicted headache yesterday ${ }^{\mathbf{a}}(\%)$ \\
\hline Any headache $(n=1858)$ & $438(23.6)$ & $3.7 \pm 4.5$ & 13.2 \\
\hline Migraine $(n=519)$ & $160(30.8)$ & $3.9 \pm 3.3$ & 13.9 \\
\hline TTH $(n=605)$ & $127(21.0)$ & $3.2 \pm 3.0$ & 11.4 \\
\hline pMOH $(n=18)$ & $13(72.2)$ & $19.7 \pm 4.1$ & 70.4 \\
\hline $\begin{array}{l}\text { Other headache on } \\
\geq 15 \mathrm{~d} / \mathrm{m}(n=73)\end{array}$ & $58(79.5)$ & $18.4 \pm 4.3$ & 65.7 \\
\hline $\mathbf{U d H}(n=601)$ & 68 (11.3) & $1.9 \pm 2.2$ & 6.6 \\
\hline
\end{tabular}

${ }^{a}$ calculated as $\mathrm{F} / 28$; $T \mathrm{HH}$ tension-type headache, $\mathrm{pMOH}$ probable medication-overuse headache, $d / m$ days/month, UdH undifferentiated headache

headache on $\geq 15$ days/month (5.4\% [3.8-7.6\%]), both high, but both very feasible in this former USSR country because they are similar to estimates in Russia from another Global Campaign study with the same methodology [22]. The concern generated is that we see, in our study, rapidly escalating prevalences of these disorders in adolescents. Whatever causes there may be for highly frequent headache, there is a suspicion that medication overuse is, at least in part, a behaviour learned by children and adolescents from their parents.

We need to comment on the over-reporting of HY by those with migraine (especially), TTH and UdH. The reported headache frequencies over the enquiry period of 28 days were perfectly feasible for all headache types; where there is conflict between these and reports of HY - essentially, for the episodic headaches - the former seem more probably correct despite that recall error should be greatly diminished in the latter. In adult studies, it should be noted, frequencies recalled over enquiry periods of 90 days have rather closely matched the reporting of HY, at least for all headache [23-26]. There are no published data on $\mathrm{HY}$ in younger age groups for comparison. We offer two explanations, neither very convincing but each, perhaps, a factor. First, children in particular tend to believe there are "right" and "wrong" answers (especially with yes/no questions), and may be influenced accordingly, more so perhaps in a school setting where they are used to taking tests. Second is sympathy-seeking by children who have just been describing their headaches.

The strengths of this study lie in its tested and validated methodology $[11,12,15]$ and adequate sample size. Mandatory institutional schooling ensured the validity of schools-based sampling [14]: the exclusion of, at most, $10 \%$ of 17 -year-olds would have introduced negligible if any bias. But the non-participation proportion of almost one third (32.6\%) was a significant study limitation. It is clear that this introduced a gender-bias (nonparticipation was higher among males), but statistical correction could deal with this. We could not know whether there were other resulting biases, or, if there were, what influence they might have had. Parental consent was not forthcoming from almost one quarter (24.2\%) of pupils - the primary cause of this problem. This will always be an obstacle to research in these age groups while prior written parental consent is required. It is not, generally, that parents object: they simply fail to register agreement. In non-invasive research of negligible risk to the individual and performed with the objective of benefiting large groups, ethics committees might consider giving parents opportunity to object and, in default, allowing the research with the participants' own consent.

\section{Conclusions}

Headache has, again, been shown to be common in children and adolescents, and undifferentiated headache has been confirmed as a headache type that must be recognised and included in accounts of headache in these age groups. These findings are of importance to Lithuania. They also contribute to knowledge and understanding of child and adolescent headache globally.

\section{Acknowledgements}

We are grateful to Professors Çiçek Wöber-Bingöl and Christian Wöber for their contributions to study conception and design. We thank the pupils and staff of the participating schools for their cooperation in this study.

\section{Authors' contributions \\ TJS and NV-M conceived the study. TJS, DG, AZ and NV-M developed the protocol. DG, AZ and NV-M validated the Lithuanian version of the questionnaire. DG and NV-M administered the survey and collected the data in Lithuania, with DU coordinating the global programme. TS and AYT performed the statistical analysis, with input from AZ and interpretation by TJS. TJS drafted the manuscript. All authors contributed to manuscript revision and approved the final version. \\ Funding \\ None. \\ Availability of data and materials \\ The data are held on file at University of Mersin. Once analysis and publications are completed, they will be freely available for non-commercial}


purposes to any person requesting access in accordance with the general policy of the Global Campaign against Headache.

\section{Ethics approval and consent to participate}

The study was approved by Kaunas Regional Committee of Bioethics (BE-2-7. 26-01-2016), and authorised by Regional Education Authorities. Consent was obtained prior to inclusion from each participating child or adolescent, along with signed parental consent.

\section{Consent for publication}

Not applicable.

\section{Competing interests}

TJS is a Director and Trustee of Lifting The Burden. Otherwise, no author declares a conflict of interest.

\section{Author details}

'Department of Neurology, Faculty of Medicine, Lithuanian University of Health Sciences, Kaunas, Lithuania. ${ }^{2}$ Department of Preventive Medicine and Health Research Institute, Faculty of Public Health, Lithuanian University of Health Sciences, Kaunas, Lithuania. ${ }^{3}$ Department of Public Health, Mersin University School of Medicine, Mersin, Turkey. ${ }^{4}$ Neurology Department, Cerrahpaşa School of Medicine, Istanbul University, Istanbul, Turkey. ${ }^{5}$ Department of Neuromedicine and Movement Science, Norwegian University of Science and Technology, Edvard Griegs gate, Trondheim, Norway. ${ }^{6}$ Division of Brain Sciences, Imperial College London, London, UK.

Received: 18 April 2020 Accepted: 2 June 2020

\section{Published online: 10 June 2020}

\section{References}

1. Vos T, Flaxman AD, Naghavi M, Lozano R, Michaud C, Ezzati M, Shibuya K, Salomon JA, Abdalla S, Aboyans V, Abraham J, Ackerman I, Aggarwal R, Ahn SY, Ali MK, Alvarado M, Anderson HR, Anderson LM, Andrews KG, Atkinson C, Baddour LM, Bahalim AN, Barker-Collo S, Barrero LH, Bartels DH, Basáñez MG, Baxter A, Bell ML, Benjamin EJ, Bennett D, Bernabé E, Bhalla K, Bhandari B, Bikbov B, Bin Abdulhak A et al (2012) Years lived with disability (YLD) for 1160 sequelae of 289 diseases and injuries 1990-2010: a systematic analysis for the global burden of disease study 2010. Lancet 380:2163-2196

2. Vos T, Barber RM, Bell B, Bertozzi-Villa A, Biryukov S, Bolliger I, Charlson F, Davis A, Degenhardt L, Dicker D, Duan L, Erskine H, Feigin VL, Ferrari AJ, Fitzmaurice C, Fleming T, Graetz N, Guinovart C, Haagsma J, Hansen GM, Hanson SW, Heuton KR, Higashi H, Kassebaum N, Kyu H, Laurie E, Liang X, Lofgren K, Lozano R, MacIntyre MF, Moradi-Lakeh M, Naghavi M, Nguyen G, Odell S, Ortblad K, Roberts DA et al (2015) Global, regional, and national incidence, prevalence, and years lived with disability for 301 acute and chronic diseases and injuries in 188 countries, 1990-2013: a systematic analysis for the global burden of disease study 2013. Lancet 386:743-800

3. GBD (2015) Disease and injury incidence and prevalence collaborators (2016) global, regional, and national incidence, prevalence, and years lived with disability for 310 diseases and injuries, 1990-2015: a systematic analysis for the global burden of disease study 2015. Lancet 388:1545-1602

4. Vos T, Abajobir AA, Abate KH, Abbafati C, Abbas KM, Abd-Allah F, Abdulkader RS, Abdulle AM, Abebo TA, Abera SF, Aboyans V, Abu-Raddad $\sqcup$, Ackerman IN, Adamu AA, Adetokunboh O, Afarideh M, Afshin A, Agarwal SK, Aggarwal R, Agrawal A, Agrawal S, Ahmadieh H, Ahmed MB, Aichour MTE, Aichour AN, Aichour I, Aiyar S, Akinyemi RO, Akseer N, Al Lami FH, Alahdab F, Al-Aly Z, Alam K, Alam N, Alam T, Alasfoor D et al (2017) Global, regional, and national incidence, prevalence, and years lived with disability for 328 diseases and injuries for 195 countries, 1990-2016: a systematic analysis for the global burden of disease study 2016. Lancet 390:1211-1259

5. Stovner LJ, Nichols E, Steiner TJ, Abd-Allah F, Abdelalim A, Al-Raddadi RM, Ansha MG, Barac A, Bensenor IM, Doan LP, Edessa D, Endres M, Foreman KJ, Gankpe FG, Gururaj G, Goulart AC, Gupta R, Hankey GJ, Hay SI, Hegazy MI, Hilawe EH, Kasaeian A, Kassa DH, Khalil I, Khang Y-H, Khubchandani J, Kim YJ, Kokubo Y, Mohammed MA, Moradi-Lakeh M, Nguyen HLT, Nirayo YL, Qorbani M, Ranta A, Roba KT, Safiri S, Santos IS, Satpathy M, Sawhney M, Shiferaw MS, Shiue I, Smith M, Szoeke CEl, Truong NT, Venketasubramanian N, Weldegwergs KG, Westerman R, Wijeratne T, Xuan Tran B, Yonemoto N, Feigin VL, Vos T, Murray CJL (2018) Global, regional, and national burden of migraine and tension-type headache, 1990-2016: a systematic analysis for the global burden of disease study 2016. Lancet Neurol 17:954-976

6. GBD (2017) Disease and injury incidence and prevalence collaborators (2017) global, regional, and national incidence, prevalence, and years lived with disability for 354 diseases and injuries for 195 countries and territories, 1990-2017: a systematic analysis for the global burden of disease study 2017. Lancet 392:1789-1858

7. Steiner TJ (2004) Lifting the burden: the global campaign against headache. Lancet Neurol 3:204-205

8. Steiner TJ (2005) Lifting The Burden: the global campaign to reduce the burden of headache worldwide. J Headache Pain 6:373-377

9. Steiner TJ, Birbeck GL, Jensen R, Katsarava Z, Martelletti P, Stovner LJ (2011) The global campaign, World Health Organization and Lifting The Burden: collaboration in action. J Headache Pain 12:273-274

10. Lifting The Burden. At http://www.l-t-b.org

11. Wöber-Bingöl C, Wöber C, Uluduz D, Uygunoğlu U, Aslan T, Kernmayer M, Zesch H-E, Gerges NTA, Wagner G, Siva A, Steiner TJ (2014) The global burden of headache in children and adolescents - developing a questionnaire and methodology for a global study. J Headache Pain 15:86

12. Wöber $C$, Wöber-Bingöl C, Uluduz D, Aslan TS, Uygunoglu U, Tüfekçi A, Alp SI, Duman T, Sürgün F, Emir GK, Demir CF, Balgetir F, Özdemir YB, Auer T, Siva A, Steiner TJ (2018) Undifferentiated headache: broadening the approach to headache in children and adolescents, with supporting evidence from a nationwide school-based cross-sectional survey in Turkey. J Headache Pain 19:18

13. Philipp J, Zeiler M, Wöber C, Wagner G, Karwautz AFK, Steiner TJ, WöberBingöl C (2019) Prevalence and burden of headache in children and adolescents in Austria - a nationwide study in a representative sample of pupils aged 10-18 years. J Headache Pain 20:101

14. Stovner LJ, Al Jumah M, Birbeck GL, Gururaj G, Jensen R, Katsarava Z, Queiroz L-P, Scher Al, Tekle-Haimanot R, Wang S-J, Steiner TJ (2014) The methodology of population surveys of headache prevalence, burden and cost: principles and recommendations. A product of the global campaign against headache. J Headache Pain 15:5

15. Genc D, Zaborskis A, Vaičienè-Magistris N (2018) Translation of the child and adolescent HARDSHIP (headache-attributed restriction, disability, social handicap and impaired participation) questionnaire into the Lithuanian language and validation of its HRQOL (headache-related quality of life) scale. Int J Environ Res Public Health 15:1579

16. Peters M, Bertolote JM, Houchin C, Kandoura T, Steiner TJ (2007) Translation protocol for hybrid documents. J Headache Pain 8(suppl 1):S45-\$47

17. Headache Classification Committee of the International Headache Society (2013) The international classification of headache disorders, $3^{\text {rd }}$ edition (beta version). Cephalalgia 33:629-808

18. Steiner TJ, Gururaj G, Andrée C, Katsarava Z, Ayzenberg I, Yu S-Y, Al Jumah M, Tekle-Haimanot R, Birbeck GL, Herekar A, Linde M, Mbewe E, Manandhar K, Risal A, Jensen R, Queiroz L-P, Scher Al, Wang S-J, Stovner TJ (2014) Diagnosis, prevalence estimation and burden measurement in population surveys of headache: presenting the HARDSHIP questionnaire. J Headache Pain 15:3

19. Government of Lithuania. Oficialiosios statistikos portalas. At https://osp.stat. gov.lt/statistiniu-rodikliu-analize?hash=ae14ac43-df03-4706-9b4d-955 0008b9bc3\#/ (Accessed 2 Nov 2019)

20. Andrée C, Stovner LJ, Steiner TJ, Barre J, Katsarava Z, Lainez JM, Lair M-L, Lanteri-Minet M, Mick G, Rastenyte D, Ruiz de la Torre E, Tassorelli C, Vriezen P, Lampl C (2011) The Eurolight project: the impact of primary headache disorders in Europe, Description of methods. J Headache Pain 12:541-549

21. Rastenytė $D$, Mickevičienè $D$, Stovner $L$, Thomas $H$, Andrée C, Steiner TJ (2017) Prevalence and burden of headache disorders in Lithuania and their public-health and policy implications: a population-based study within the Eurolight project. J Headache Pain 18:53

22. Ayzenberg I, Katsarava Z, Sborowski A, Chernysh M, Osipova V, Tabeeva G, Yakhno N, Steiner TJ (2012) The prevalence of primary headache disorders in Russia: a countrywide survey. Cephalalgia 32:373-381

23. Yu S, He M, Liu R, Feng J, Qiao X, Yang X, Cao X, Zhao G, Fang Y, Steiner TJ (2013) Headache yesterday in China: a new approach to estimating the burden of headache, applied in a general-population survey in China. Cephalalgia 33:1211-1217

24. Andrée C, Steiner TJ, Barré J, Katsarava Z, Lainez JM, Lampl C, Lantéri-Minet M, Rastenyte D, Ruiz de la Torre E, Tassorelli C, Stovner LJ (2014) Headache yesterday in Europe. J Headache Pain 15:33 
25. Ayzenberg I, Katsarava Z, Sborowski A, Obermann M, Chernysh M, Osipova V, Tabeeva G, Steiner TJ (2015) Headache yesterday in Russia: its prevalence and impact, and their application in estimating the national burden attributable to headache disorders. J Headache Pain 16:7

26. Steiner TJ, Rao GN, Kulkarni GB, Gururaj G, Stovner $\sqcup$ (2016) Headache yesterday in Karnataka state, India: prevalence, impact and cost. J Headache Pain 17:74

\section{Publisher's Note}

Springer Nature remains neutral with regard to jurisdictional claims in published maps and institutional affiliations.

Ready to submit your research? Choose BMC and benefit from:

- fast, convenient online submission

- thorough peer review by experienced researchers in your field

- rapid publication on acceptance

- support for research data, including large and complex data types

- gold Open Access which fosters wider collaboration and increased citations

- maximum visibility for your research: over $100 \mathrm{M}$ website views per year

At $B M C$, research is always in progress.

Learn more biomedcentral.com/submissions 